vaginal smear, at the beginning and at the end of the clinical course, appears to be particularly helpful in the diagnosis.

\section{References}

1 Hertz R. Accidental ingestion of estrogens by children. Pediatrics 1958; 21 : 203-6.

2 Weber W W, Grossman M, Thom J V, Sax J, Chan J J, Duffy M P. Drug contamination with diethylstilbestrol. $N$ Engl J Med 1963; 268: 411-5.

3 Beas F, Vargas L, Spada R P, Merchak N. Pseudoprecocious puberty in infants caused by a dermal ointment containing estrogens. J Pediatr 1969; 75: 127-30.

4 Prouty M. Gynecomastia with pigmentation in a four year old male following stilbestrol exposure. Pediatrics 1952; 9: 55-7.
5 Fara G M, Del Corvo G, Bernuzzi S, Di Pietro C, Scaglioni S, Chiumello G. Epidemic of breast enlargement in an Italian school. Lancet 1979; ii: 295-7.

- Heller M E, Dewhurst J, Grant D B. Premature menarche without other evidence of precocious puberty. Arch Dis Child 1979; 54: 472-5.

7 Pocchiari F, Loizzo A, Macri A, Moretti G, Ortolani E, Palazzesi S. The case of nineteen brands of baby-food containing meat from estrogen treated veal in Italy. Bioassay, chemical assay, and mass spectrometry. In the proceedings of the Twenty-second Congress of the European Society of Toxicology, Dublin, 17-19 August 1981 (abstract).

Correspondence to Dr A M Pasquino, Via Deruta 19, 00181 Rome, Italy.

Received 1 June 1982

\title{
Successful treatment of gallstones with bile acids in obese adolescents
}

\author{
M PODDA, M ZUIN, M L DIOGUARDI, AND S FESTORAZZI \\ Istituto di Clinica Medica III, Universita di Milano, Italy
}

SUMMARY Six obese adolescents ( 4 girls, 2 boys) with radiolucent gallstones were treated with bile acids (chenodeoxycholic or ursodeoxycholic acid). Each had lithogenic bile and no predisposing factors for pigment stone formation. Within 12 months, the bile became unsaturated with cholesterol and the gallstones had disappeared in 4 cases and were decreased in size in two.

Cholesterol gallstones are rare in childhood even in such populations as the Pima Indians who have a high prevalence of the disease. ${ }^{1}$ Nevertheless, obesity predisposes to early appearance. ${ }^{2}$

In obese adults cholesterol gallstones exhibit a poor response to treatment with bile acids, since secretion of lithogenic bile persists even if high doses of chenodeoxycholic acid (CDCA) are administered. ${ }^{3}$

Six adolescents under age 14 years have been referred to our outpatient clinic for treatment of symptomatic radiolucent gallstones during the last 3 years. Each was obese and had bile supersaturated with cholesterol.

Treatment with bile acids, CDCA, or ursodeoxycholic acid (UDCA) was successful, and the bile, initially lithogenic, became unsaturated with cholesterol, and gallstones disappeared or decreased in size between 6 and 12 months later.

\section{Patients, methods, results}

The clinical data for the patients are shown in Table 1. In each case, gallstones were suspected on the basis of at least one episode of biliary colic and were diagnosed by cholecystography. Stone radiolucency was confirmed by plain $x$-ray films of the abdomen. Liver function tests, plasma cholesterol levels, and triglycerides were normal. Erythrocyte defects leading to increased haemolysis could be excluded by indices of erythrocytes, reticulocyte

Table 1 Clinical data and effect of treatment

\begin{tabular}{|c|c|c|c|c|c|c|c|c|c|c|}
\hline \multirow[t]{2}{*}{ Case } & \multirow{2}{*}{$\begin{array}{l}\text { Age } \\
\text { (years) }\end{array}$} & \multirow[t]{2}{*}{$\operatorname{Sex}$} & \multirow{2}{*}{$\begin{array}{l}\text { Ideal weight } \\
(\%)\end{array}$} & \multirow{2}{*}{ Drug } & \multicolumn{2}{|l|}{ Stones } & \multicolumn{2}{|c|}{ Response (dissolution) } & \multicolumn{2}{|c|}{ Saturation index } \\
\hline & & & & & Number & $\operatorname{Size}^{*}(\mathrm{~mm})$ & 6 months & 12 months & Before & After \\
\hline $\begin{array}{l}1 \\
2 \\
3 \\
4 \\
5 \\
6\end{array}$ & $\begin{array}{l}12 \\
12 \\
13 \\
14 \\
11 \\
14\end{array}$ & $\begin{array}{l}\mathbf{F} \\
\mathbf{M} \\
\mathbf{F} \\
\mathbf{F} \\
\mathbf{F} \\
\mathbf{M}\end{array}$ & $\begin{array}{l}144 \\
139 \\
153 \\
145 \\
136 \\
130\end{array}$ & $\begin{array}{l}\text { CDCA } \\
\text { CDCA } \\
\text { CDCA } \\
\text { UDCA } \\
\text { UDCA } \\
\text { UDCA }\end{array}$ & $\begin{array}{l}\text { Single } \\
\text { Multiple } \\
\text { Multiple } \\
\text { Single } \\
\text { Multiple } \\
\text { Single }\end{array}$ & $\begin{array}{r}10 \\
8 \\
5 \\
12 \\
5 \\
9\end{array}$ & $\begin{array}{l}\text { Partial } \\
\text { Complete } \\
\text { Complete } \\
\text { Partial } \\
\text { Complete } \\
\text { Partial }\end{array}$ & $\begin{array}{l}\text { Complete } \\
\overline{-} \\
\text { Partial } \\
- \\
-\end{array}$ & $\begin{array}{l}1 \cdot 55 \\
1 \cdot 28 \\
1 \cdot 31 \\
1 \cdot 47 \\
1 \cdot 20 \\
1 \cdot 25\end{array}$ & $\begin{array}{l}0.93 \\
0.65 \\
0.85 \\
0.82 \\
0.71 \\
0.60\end{array}$ \\
\hline
\end{tabular}

CDCA $=$ chenodeoxycholic acid, UDCA $=$ ursodeoxycholic acid.

*Size, diameter of largest stone. 
count, haemoglobin electrophoresis, and osmotic fragility.

The cholesterol saturation index was calculated according to Carey ${ }^{4}$ on bile-rich duodenal aspirates. Gallbladder contraction was induced by intramuscular injection of caerulein $(0 \cdot 3 \mu \mathrm{g} / \mathrm{kg}$ Ceruletide, Farmitalia, Milan, Italy). In each case the bile was supersaturated with cholesterol (Table 1). Cases 1-3 were treated with CDCA, and Cases 4-6 with UCDA after it had become commercially available; it was chosen because it is generally better tolerated than CDCA. Each bile acid was administered at a dose of about $15 \mathrm{mg} / \mathrm{kg}$ a day, at meals. Although all patients were advised to follow calorie-restricted diets, none substantially lost weight. The saturation index was again measured 6-8 weeks after starting treatment: the bile had become unsaturated in all cases (Table 1). The percentage of biliary bile acids was determined by gas-liquid chromatography before and during treatment (Table 2).

Both CDCA and UDCA became predominant in bile, whereas lithocholic acid did not show any major change during either treatment.

In order to assess the response in terms of stone dissolution, cholecystograms were repeated at 6monthly intervals. Four patients showed complete dissolution; this was achieved by 3 patients at 6 months, and by the fourth at 12 months (Table 1). Disappearance of stones was confirmed by ultrasonography and treatment was stopped 3 months later. The remaining two (Cases 4 and 6, Table 1) showed partial dissolution. Each had a single stone the diameter of which decreased from 12 to 7 $\mathrm{mm}$ and from 9 to $4 \mathrm{~mm}$ after 6 months. In Case 4, a further reduction in size to $3 \mathrm{~mm}$ was noted at 12 months. These 2 patients are still undergoing treatment.

UDCA was well tolerated, but diarrhoea and abdominal discomfort were experienced by 2 of the 3 patients who were given CDCA. Such symptoms

Table 2 Biliary bile acid composition before and after treatment

\begin{tabular}{llrlrll}
\hline Case & & $C A$ & $C D C A$ & $D C A$ & $L C A$ & $U D C A$ \\
\hline 1 & Before & $53 \cdot 3$ & 30 & $15 \cdot 4$ & $0 \cdot 8$ & $0 \cdot 5$ \\
2 & After & $6 \cdot 4$ & $85 \cdot 7$ & $3 \cdot 5$ & $1 \cdot 4$ & 3 \\
2 & Before & 27 & 39 & $30 \cdot 1$ & $3 \cdot 2$ & $0 \cdot 7$ \\
& After & 3 & 90 & $2 \cdot 8$ & $3 \cdot 7$ & $0 \cdot 5$ \\
3 & Before & 35 & 27 & $35 \cdot 6$ & $1 \cdot 4$ & $1 \cdot 0$ \\
& After & $4 \cdot 5$ & $89 \cdot 5$ & $2 \cdot 6$ & 2 & $1 \cdot 4$ \\
4 & Before & $38 \cdot 6$ & $42 \cdot 4$ & $15 \cdot 7$ & $2 \cdot 7$ & $0 \cdot 6$ \\
& After & $8 \cdot 2$ & $21 \cdot 1$ & $5 \cdot 1$ & $2 \cdot 6$ & 63 \\
& Before & $31 \cdot 8$ & $35 \cdot 1$ & $27 \cdot 8$ & $4 \cdot 1$ & $1 \cdot 2$ \\
6 & After & $10 \cdot 2$ & $19 \cdot 2$ & $10 \cdot 6$ & $4 \cdot 2$ & $55 \cdot 8$ \\
& Before & $35 \cdot 5$ & $28 \cdot 5$ & $32 \cdot 8$ & 3 & $0 \cdot 2$ \\
& After & $8 \cdot 6$ & $20 \cdot 1$ & $7 \cdot 8$ & $3 \cdot 5$ & 60 \\
\hline
\end{tabular}

$\mathrm{CA}=$ cholic acid, $\mathrm{CDCA}=$ chenodeoxycholic acid, $\mathrm{DCA}=$ deoxycholic acid, LCA = lithocholic acid, UDCA = ursodeoxycholic acid. were worse during the first weeks of treatment. Hypertransaminasaemia was noted in Case 2 after 6 weeks, but later the transaminase values were normal.

\section{Discussion}

Treatment with bile acids is an alternative to surgery for cholesterol stones alone, and these are radiolucent on $x$-ray films. In adults about $15 \%$ of radiolucent stones are pigment stones but in adolescents pigment stones are more common than cholesterol stones. ${ }^{5}$ However secretion of lithogenic bile and the absence in the adolescent of any of the factors predisposing to pigment stone formation ${ }^{1}$ are additional criteria for medical treatment of gallstones in adolescents.

The positive response to bile acid administration shows that the gallstones in our patients were of cholesterol, thus confirming that in childhood, as well as in adulthood, obesity is a major risk factor for early development of cholesterol lithiasis, as was suggested by Honoré ${ }^{2}$ on the basis of studies on adolescent girls. We have studied only a few such cases, but our high success rate should be applicable to this population as a whole.

The changes in the composition of biliary bile acids were similar to those observed in adults during treatment with equal doses of CDCA or UCDA, ${ }^{6}$ and bile became consistently unsaturated with cholesterol regardless of which bile acid was administered. This differs from the findings in obese adults treated with CDCA. ${ }^{3}$ It is therefore likely that in obese adolescents cholesterol synthesis or secretion is more sensitive to inhibition by bile acid administration than in obese adults treated with CDCA.

No information is available about the rate of recurrence after stone dissolution in adolescents and long-term safety of bile acid administration has not been firmly established. There is evidence that links colorectal cancer with exposure to dihydroxy-bile acids, ${ }^{7}$ but this relationship has not been demonstrated after administration to humans; however cholecystectomy is associated with a higher prevalence of colon cancer. ${ }^{8}$

We conclude that treatment with bile acids should be considered for obese adolescents with radiolucent gallstones and that UDCA is to be preferred to CDCA because of its better tolerance.

\footnotetext{
References

1 Bennion L J, Grundy S M. Risk factors for the development of cholelithiasis in man. II. N Engl J Med 1978; 299: 1221-7.

2 Honoré L H. Cholesterol cholelithiasis in adolescent females. Arch Surg 1980; 115: 62-4.

3 Iser J H, Maton P N, Murphy G M, Dowling $\mathbf{R} \mathbf{H}$. Resistance to chenodeoxycholic acid (CDCA) treatment
} 
in obese patients with gallstones. $\mathrm{Br} \operatorname{Med} J$ 1978; i: 1509-12.

4 Carey M C. Critical tables for calculating the cholesterol saturation of native bile. J Lipid Res 1978; 19: 945-55.

5 MacMillan $R$ W, Schullinger J N, Santulli T V. Cholelithiasis in childhood. Am J Surg 1974; 127: 689-92.

6 Stiehl A, Czygan P, Kommerell B, Weis H J, Holtermüller K G. Ursodeoxycholic acid versus chenodeoxycholic acid: comparison of their effects on bile acid and bile lipid composition in patients with cholesterol gallstones. Gastroenterology 1978; 75: 1016-20.
7 Reddy B S, Wynder E L. Metabolic epidemiology of colon cancer. Fecal bile acids and neutral sterols in colon cancer patients, and patients with adenomatous polyps. Cancer $1977 ; 39: 2533-9$.

8 Linos D A, O'Fallon W M, Beart R W, Jr, Beard C M, Dockerty $M$ B, Kurland L T. Cholecystectomy and carcinoma of the colon. Lancet 1981; ii : 379-81.

Correspondence to Dr M Podda, Istituto di Clinica Medica III, 15 Via Pace, 20122 Milano, Italy.

Received 16 July 1982

\title{
Prenatal exclusion of severe combined immunodeficiency
}

\author{
R J LEVINSKY, D C LINCH, C L BEVERLY, AND C RODECK \\ Institute of Child Health and The Hospital for Sick Children, University College Hospital Medical School, and \\ King's College Hospital Medical School, London
}

\begin{abstract}
SUMMARY By analysing leucocyte subpopulations with monoclonal antisera, we have shown that the diagnosis of severe combined immunodeficiency can be made soon after birth. The technique of staining has been adapted for small blood samples, and normal ranges of leucocyte subpopulations have been established for fetal blood taken from midtrimester pregnancies. Using this information, we gave prenatal advice to an at risk family and predicted that the pregnancy would be normal; this was confirmed after birth. This technique should allow prenatal diagnosis for severe combined immunodeficiency, especially if the phenotype of a previously affected child is known.
\end{abstract}

Severe combined immunodeficiency (SCID) is a heterogeneous syndrome inherited either as an $\mathrm{X}$-linked or an autosomal recessive disorder. Affected children lack both cell-mediated and humoral immunity; they present with repeated viral, bacterial, or fungal infections, have protracted diarrhoea, and failure to thrive. ${ }^{1}$ Unless treated by bone marrow transplants the children generally die within the first year of life.

Most patients have an absolute deficiency of T-cell numbers with numbers of B-cells being absent, very low, or very high. Within families a similar pattern of T- and B-cell numbers is observed in affected individuals (personal experience of six families with more than one affected child). In $20 \%$ of the autosomal recessive type, the disease is caused by a deficiency of adenosine deaminase, and in such families prenatal diagnosis demonstrates lack of the enzyme in amniotic cells. ${ }^{2}$ Prenatal diagnosis is not yet available for the remaining cases. However, the development of monoclonal antibodies which distinguish leucocyte populations, and in particular T-cell subsets, has enabled normal ranges to be established in healthy children and adults (unpublished). Similarly, the diagnosis of various forms of immunodeficiency can be made by analysing lymphocyte phenotypes. We have recently developed a method for analysing the phenotype of leucocytes from very small samples of blood using monoclonal antibodies and a fluorescent activated cell sorter. Using this technique, normal ranges for leucocyte populations have been established in the second trimester of pregnancy on fetal blood samples $(100-500 \mu \mathrm{l})$ obtained at fetoscopy for diagnosis of thalassaemia and haemophilia. ${ }^{3}$ It is therefore possible, if one knows the phenotype of a previously affected sibling, to offer prenatal advice to an at risk family during a second pregnancy.

\section{Methods}

Staining mononuclear cells. Venous blood specimens were obtained from 2 children with SCID in the first 2 days of life, and from 5 others below the age of 6 months. Mononuclear cells were obtained by Ficoll-Triosil centrifugation and after washing were stained with monoclonal mouse antisera (aliquots of cells at $2 \times 10^{5} / \mathrm{ml}$ ) to human leucocyte subpopulations. The following antisera were used: (1) UCHT1 which recognises all mature T-cells. ${ }^{4}(2)$ Leu $3 a$ which recognises helper/inducer T-cells. ${ }^{5}$ (3) Leu $2 \mathrm{a}$ which recognises suppressor/cytotoxic T-cells. ${ }^{5}$ (4) DA2 which recognises a non-polymorphic determinant of HLA Dr antigen. ${ }^{6}(5)$ OKM1 which recognises cells of the monocytic series, some granulocytes, and cells with natural killer activity. ${ }^{7}$ (6) Anti Hle-1 which reacts with all peripheral blood leucocytes. ${ }^{4}$

B-cells were recognised by staining surface immunoglobulin-bearing cells with fluorescent-labelled rabbit or sheep antihuman immunoglobulin (Wellcome Laboratories).

The cells stained with monoclonal antisera were 